\title{
Occurrence of Rhamphospora nymphaeae on Nymphaea tetragona in Korea
}

\author{
Mi-Jeong Park ${ }^{1}$, Cvetomir M. Denchev ${ }^{2}$, Kyung-Sook Han ${ }^{3}$ and Hyeon-Dong Shin ${ }^{1 *}$ \\ ${ }^{1}$ Division of Environmental Science and Ecological Engineering, Korea University, Seoul 136-701, Korea \\ ${ }^{2}$ Institute of Botany, Bulgarian Academy of Sciences, 1113 Sofia, Bulgaria \\ ${ }^{3}$ Horticultural \& Herbal Environment Division, National Institute of Horticultural and Herbal Science, Suwon 441-440, Korea
}

(Received on February 14, 2010; Accepted on July 5, 2010)

Pygmy water lily (Nymphaea tetragona) is a perennial aquatic herb with floating leaves and beautiful flowers, belonging to the Nymphaeaceae. It is widely planted in ponds and water gardens for ornamental purposes worldwide. In October 2009, light colored spots with necrotic lesions were found on the leaves in a private water garden in Yangpyeong, Korea (Fig. 1A). Simple microscopic examination yielded evidence that the spots are associated with infections by Rhamphospora nymphaeae. Further survey in Suwon and Daejeon showed that the disease is rather common in Korea. Voucher specimens were deposited in Korea University (KUS-

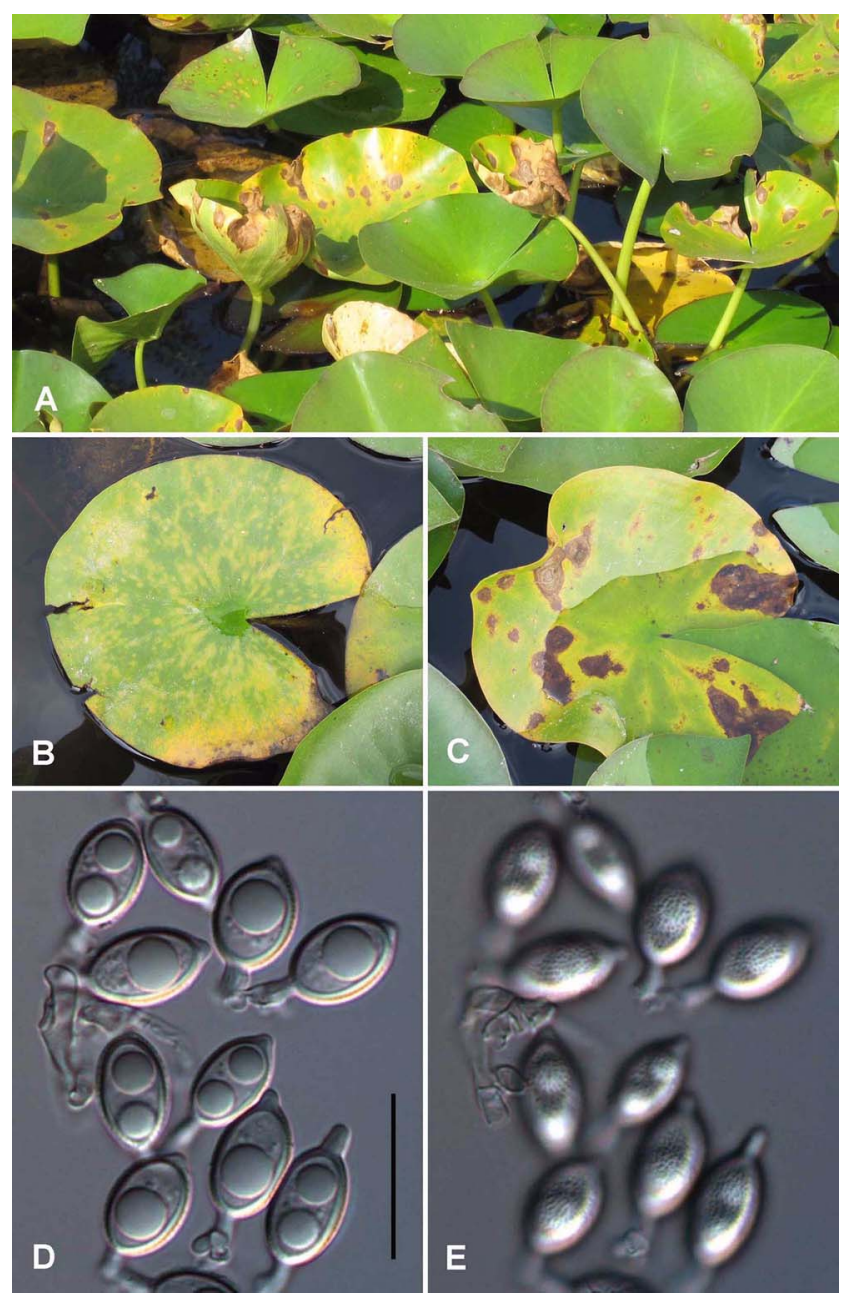

Fig. 1. Heavy infections of Rhamphospora nymphaeae on Nymphaea tetragona (A), showing typical light colored spots (B) and later necrotic lesions (C) on leaves. (D \& E) Spores compared in different focus, displaying minutely verruculose cell walls (E). Bar $=20 \mu \mathrm{m}$.
F24750, F24782). To identify the fungus, the spores embedded in the mesophyll of leaves were mounted in lactophenol solution on glass slides, gently heated to boiling point and then cooled. The measurements of spores are given in the form: min-max (mean \pm 1 standard deviation). Fresh material was used for photomicrography of the spores.

Sori in leaves cause round, ovoid or irregular spots, 1-7 mm long, larger by fusion, most prominent on the under side, yellowish brown or with age reddish brown, scattered or confluent, with age often perforate. Spores are embedded in the host tissues, solitary, ellipsoidal, rarely broadly ellipsoidal or subglobose, with an apical papilla (0.5-1.5 $\mu \mathrm{m}$ high) and a basal appendage from a remnant of the sporogenous hypha (because of their presence, spores usually described as lemon-shaped), 10-17.5 (including the papilla length) $\times 7-9(13.0 \pm 1.5 \times 8.1 \pm 0.5) \mu \mathrm{m}(n=50)$, with pale, yellowish brown walls and one or two, large drops in the hyaline cytoplasm; spore wall $c a 1.5(-2) \mu \mathrm{m}$ thick, as seen by LM, two-layered, outer layer smooth, inner layer minutely verruculose (Fig. 1D \& E). These characteristics of the fungus are similar to data of previous records of Rhamphospora nymphaeae D.D. Cunn. [ E Entyloma nymphaeae (D.D. Cunn.) Setch.] (Piepenbring, 2003; Vánky, 2002).

The spores are formed subterminally on the branches of ramified sporogenous hyphae, especially in the large air-canals but also in any free space between cells of the leaf(Vánky, 2002), thus causing yellowish brown spots which are reddish brown with age and finally develop into necrotic lesions (Fig. 1B \& C). The smut fungus has been recorded on nymphaeaceous hosts including Castalia, Nuphar and Nymphaea (Farr and Rossman, 2010; Vánky, 2002). Nymphaea tetragona was recorded as host plant of this smut fungus from Japan (Katsuki, 1953). To our knowledge, this is the first report of this smut fungus as well as its host plant in Korea. The smut infections greatly detract from the beauty of glossy leaves of this plant. As far as we observed in several places in Korea, the smut infection of pygmy water lily seems to be rather common and is a potential threat to commercial production of the seedlings.

\section{References}

Farr, D. F. and Rossman, A. Y. 2010. Fungal Databases, Systematic Mycology and Microbiology Laboratory, ARS, USDA. Retrieved February 10, 2010, from http://nt.ars-grin.gov/fungaldatabases/

Katsuki, S. 1953. Notes on some new or noteworthy fungi in Kyushu (5). Kyushu Agricultural Research 11:41-42.

Piepenbring, M. 2003. Smut Fungi (Ustilaginomycetes p.p. and Microbotryales, Basidiomycota). In: Flora Neotropica, Monograph 86 . The New York Botanical Garden Press, Bronx, N.Y.

Vánky, K. 2002. Illustrated Genera of Smut Fungi. $2^{\text {nd }}$ edn. APS Press, St. Paul, Minnesota, USA.

\footnotetext{
*Corresponding author (hdshin@korea.ac.kr)
} 